\title{
Political space and the space of polities: Doing politics across nations ${ }^{\text {ts }}$
}

\author{
Marion Fourcade ${ }^{\mathrm{a}, *}$, Brian Lande ${ }^{\mathrm{b}}$, Evan Schofer ${ }^{\mathrm{c}}$ \\ a University of California, Berkeley, United States \\ ${ }^{\mathrm{b}}$ Polis Solutions, Seattle, WA, United States \\ ${ }^{\mathrm{c}}$ University of California, Irvine, United States
}

\section{A R T I C L E I N F O}

\section{Article history:}

Received 2 July 2014

Received in revised form 17 December 2015

Accepted 17 December 2015

Available online 10 February 2016

\section{Keywords:}

Bourdieu

Comparative methods

Political sociology

Relationalism

World Values Survey

\begin{abstract}
A B S T R A C T
What makes political life in the United States so different from political life in France, Hungary or Argentina? This paper considers why societies "do politics" differently. We draw on Pierre Bourdieu's criticism of substantialist thinking in sociology and on his conceptualization of the social space to propose a new way of relating methodological to theoretical claims in comparative political sociology. We do this by exploring and constructing a "space of polities" based on data from the 2004 World Values Survey, using relational statistical techniques (e.g., geometric data analysis). The main insight is that any single form of political action (e.g., joining a voluntary association, or a demonstration, or a boycott) only takes its meaning in the context of its objective relationship to other forms of political action and non-action that have currency in each particular society. We explore the diversity of polity types that actually exist and discuss how they emerge from similar configurations in countries' spaces of political practices. We suggest that the reason for such clustering lies in similar political-historical trajectories. We conclude by arguing for a comparative approach that is sensitive to differences in overall systems of relationships.
\end{abstract}

(c) 2015 Elsevier B.V. All rights reserved.

\section{Introduction}

There are three main ways of conceiving social "groupness" in sociology: groups can be defined by actual patterns of social interaction between individuals, by patterns of similarity and difference in shared individual characteristics (e.g. gender, age), or by patterns of similarity and difference in behavior (people who "do" or "don't do" certain kinds of things, e.g. churchgoers or non-voters). In the first instance, the driving metaphor is that of a social network of interconnectedness; the second model proposes an a priori, theoretical reading of groupness; the third constructs groupness on the basis of shared observable behavior (see Bourdieu, 1984; De Nooy, 2003; Vaisey \& Lizardo, 2010; Goldberg, 2011: 1399). For instance, we can imagine membership in groups of musical listeners as an actual group of people who discuss or listen to music or go to concerts together, as a pre-existing, theoretical group whose characteristics we think are relevant for the differentiation of musical styles and marketing (e.g. African Americans); or as an analytical group constructed on the basis of a whole range of

\footnotetext{
t3 We thank Andrew Perrin, Arthur Stinchcombe, Brigitte Leroux, Claude Fischer, Daniel Kluttz, Donald Broady, Jeffrey Sallaz, John W. Meyer, Kieran Healy, Mikael Borjesson, Paul DiMaggio, Steven Lukes, Sun Kim and the late Charles Tilly for helpful comments on this paper. An earlier version of this article was presented at the 2007 Annual Meeting of the American Sociological Association.

* Corresponding author at: Department of Sociology, UC Berkeley, Barrows Hall 410, Berkeley, CA 94720-1980, United States. Fax: +1 5106420659.

E-mail addresses: fourcade@berkeley.edu (M. Fourcade), brian.lande@polis-solutions.com (B. Lande), schofer@uci.edu (E. Schofer).
} 
music-related practices and tastes (e.g. jazz fans). All individual practices - cultural, political, economic - in fact can be apprehended in these three fundamental ways.

In this article, we explore the consequences of the third approach for analyzing how people "do politics" across nations. We treat politics as a "space" of practices, grouping people on the basis of their observed behavior on a range of political activities. We represent a nation's space of political practices as an emergent system of empirical relations of distance and proximity. We ask: which types of political activities hang together empirically? For instance, are people who sign petitions also likely to participate in boycotts? The answer, it turns out, varies across nations. Countries differ not only in the relative prominence of different types of political activities (e.g. the Swedes are more likely to be joiners than the Spanish), but also in the relationships that these activities have with each other (e.g., in Sweden, joining an association does not necessarily mean participating actively in it; in the US, it frequently does).

Comparing nations "space to space" - rather than "practice to practice" - offers a way of understanding cross-national differences in political activity that is more attentive to the cultural experience of politics in different social contexts. In short, this approach is attuned to the empirical meaning of politics as expressed in people's strategies of action (or inaction) (Swidler, 1986). Taken together and understood in a relational sense, a patterned field of political "skills, habits, and styles" (ibid., 275) forms what we may call a political culture.

Our goal is thus to acknowledge both the fundamental diversity of political activities within nations and the stable patterning of this diversity across nations. Using cross-national data on political practices, we elicit an inductive conceptualization of the systematic ways in which nations may differ or resemble one another, "space to space": countries that load together in the cross-national analysis should look broadly similar in the within-country analyses while retaining specific features that are the product of their specific historical trajectories and culture. At the cross-national level, we find that countries differ mainly in terms of the volume and temporal structure of the political activities that take place on their soil. But how can we explain these patterns theoretically? Relying on the work of Jepperson (1993, 2002) and Jepperson and Meyer (1991), we show that the underlying structure of difference and similarity across nations reflects, in part, historically evolved variations in the extension, organization and meaning of community and authority across countries, or the institutional shape of the national "polity" (Parsons, 1963). More specifically, we relate individual civic orientations as expressed in various types of political behaviors to national differences in political integration, in the location of political sovereignty (in the state versus society), and in dominant modes of interest representation (associational versus corporate). As Jepperson $(1993,1)$ puts it, "differing types of modern nation-states produce distinctive kinds of public behavior and talk."

\section{From substantialism to relationalism}

Pierre Bourdieu famously opposed what he called "substantialism", or "nominal relativism" - that is, the tendency to give ontological priority to things (parties, associations, organizations, etc.) - to his own "relationalism." Substantialism typically proceeds by defining or describing the properties (historical, organizational, cultural, etc.) of things prior to their being in interaction or in relation to other entities (Desmond, 2014; Emirbayer, 1997; Martin, 2003). A strictly substantialist reading on political mobilization would, for instance, emphasize the rise of grievances, the organizational strategies of individual movements, the 'identity' or the emotional engagement of their members, as inherent qualities and sui generis explanations for outcomes.

But just like psychological processes are insufficient to explain individual behavior (Durkheim, 1997), internal processes hardly account for why social movements do what they do. So analysts have introduced a range of relational considerations to public authorities, powerful patrons, public opinion, other social movements, or indeed the whole "political opportunity structure" - to understand what drives the "dynamics of contention." (McAdam, Tarrow, \& Tilly, 2001) Such relations, however, are generally conceptualized in interactive terms rather than in structural ones (i.e. in terms of actual connection rather than relations of behavioral distance and proximity). Thus, their focus tends to be on processes of diffusion and mutual influence between movements, on the circulation of repertoires as they are being publicly performed (e.g. Tilly, 2008), or on state-movements relations.

Although concrete networks of relations are often at play in politics (e.g. see Mische, 2007), the fact is that individuals and groups may position themselves in relation to one another without having a personal connection - workers vis-à-vis their abstract bosses ("shareholders", "capitalists"), women and men as categories vis-à-vis one another, or Catholics versus Protestants. More prosaïcally, the people who claim to like "anything but heavy metal” (Bryson, 1996) do not simply state a negative relation to the acoustic properties of this particular music style: their "dislike" may express, fundamentally, a distant relation to heavy metal listeners and their underlying social properties (in this case a lower class/lower education background), which are pervasively intertwined with people's understanding and appreciation of the music. Likewise, we can assume that those people who state in the World Values Survey that they "would never sign a petition" do not express a personal relationship to the abstract object "petition," but rather a relation of distance to the (perceived) social properties of the people who sign petitions. In other words, political position-takings, like all likes and dislikes, act as symbolic markers of membership in categories of people, rather than as expressions of purely individual, disembedded political preferences (Emirbayer \& Goldberg, 2005). In another telling illustration, Eliasoph (1998) finds that voluntary association members in the United States make sure to articulate their public concerns in a very private way, explicitly eschewing the language of 
politics because they fear being perceived as 'activists' as opposed to belonging to the more palatable category of "selfinterested citizens."

The broader point is that what heavy metal represents, or what signing a petition means, depends, respectively, on the whole social structure of the space of musical tastes, and the whole structure of the space of political practices, which of course also varies across countries depending on specific institutional configurations and embodied collective representations (Eliasoph \& Lichterman, 2003). We can better comprehend what petitioning or striking means by placing each practice not only in relation to the particular institutional context and political opportunity structure in which it is embedded, but also in relation to the whole space of political likes and dislikes, actions and non-actions, possibilities and impossibilities, which are readily observable in that context. In this respect we follow not only Bourdieu but many other sociologists who, especially in the study of cultural tastes (Breiger, 2000; Lena \& Petersen, 2008; Petersen \& Kern, 1996; Vaisey \& Lizardo, 2010; Goldberg, 2011) or systems of belief and meaning (Mohr, 1998; Martin, 2000; Mohr \& Bogdanov, 2013; Ghaziani \& Mohr, 2014) use quantitative tools to map shared patterns of practice or understanding (also see Silber, 1995 on the use of spatial metaphors in sociology).

\subsection{From Politics on Paper to the Space of Political Practices}

One of the best illustrations of the difference between the two analytical strategies (substantialist versus relational) can be found in Pierre Bourdieu's critique and re-conceptualization of class analysis (see especially 1984,1985). Marxist analysis, Bourdieu argues, provides us with a theoretical vocabulary for talking about classes as defined by certain properties (e.g. the relationship to the means of production) and for analyzing what happens to classes (defined in this way) as they interact with one another. But Marxist "classes" are abstract constructions, "classes on paper" (Bourdieu, 1985, p. 725) whose "groupness" is derived from a theoretical position rather than from the empirical reality of practices. "Social classes do not exist.... What exists is a social space, a space of differences, in which classes exist in some sense in a state of virtuality, not as something given but as something to be done" (Bourdieu, 1998, p. 12, emphasis in text).

From this point of view, two individuals who share a similar position in social space, whether this position is defined onedimensionally (e.g. in terms of ownership of the means of production) or multi-dimensionally (e.g. in terms of relative endowments in economic, cultural and social capital), do not naturally form a group. What creates "groupness" is, first, the fact that the probability to coalesce (that is, to form institutionalized entities) rises with social proximity: the aforementioned socio-demographic qualities will, under particular circumstances, translate into empirical proximity. Additionally, there is the cultural labor of group making, the institutionalization of stable properties to cover an otherwise disparate aggregate of individuals through the objectification of new representations (through performative acts and phrases-e.g. "workers of the world, unite!"), organizations (with chairs, delegates, members, etc.), and symbols (Bourdieu, 1985; Brubaker, 2004; Garfinkel \& Rawls, 2002; Sewell, 1996; Swartz, 2013; Wedeen, 2002).

Finally, groupness emerges from the shared subjective construction of the objective world (Bourdieu, 1985, p. 727). It is the actors' perceptions of the social world - which are themselves relationally determined through the practical experience of this world, particularly the struggles, conscious and unconscious, over the distribution of symbolic power (i.e. the power to name, categorize, label, and institute) - that contribute to produce and reproduce relatively stable relationships (which may therefore take on an "objective" character). One of the greatest achievements of Distinction comes from making such concrete groupings visible by grounding the notion of class in the unconscious "collective orchestration of practices" rather than in conscious, purposive collective action. Classes, in this perspective, are the empirically realized sharing of certain lifestyles and social properties. Rather than being posited a priori, coherence emerges from the actual practices of agents that is, from the empirical analysis of social closeness or distance (where distance is measured by using some form of geometric data analysis.)

What does all this have to do with politics? We may proceed by analogy here. From a relational point of view, a sociology that defines its object to be the study of "social movements" or "social capital" or "voluntary associations" is just as problematic as Marxist class analysis-and for the same reasons. Treating different forms of political activity as pre-existing, unproblematic constructs makes the relational moment secondary to (i.e. a consequence of) the definitional one. Furthermore, such a strategy establishes the a priori comparability of objects across polities that may largely obscure the true empirical differences, which are not to be found in the objects as such, but instead in the relational space within which these objects get constituted. Each form of political activity (e.g. demonstrations, voting, voluntary associations' membership) is merely a point in a space of relations whose shape and structure still needs to be determined.

Spaces of political practices may thus be constructed out of a wide array of indicators. Examples include the types of commitments (in time or money) people make in such practices, the types of actions they carry out (participating in demonstrations, strikes, sit-ins; signing petitions; writing checks; issuing statements); the types of organizations involved (e.g. public or private; large or small); and the social characteristics of their members or leaders. Correlatively, it is this space, this totality, which ought to constitute the true object of study-both what needs to be explained and what explains the nature and shape of the constitutive elements.

One great advantage of such an analytical position is that it allows for a rather capacious definition of the political. Thus in his holistic treatment of "democracy in America," de Tocqueville (2000) saw the benefits of integrating into his analysis such different objects as the media, associations, the courts, the voting system, and administrative structures. Likewise, we should try to incorporate as many varied types of data as possible to map out, for selected nations, a space of political practices. 
(Ancelovici, 2009) Such a strategy is analogous to Bourdieu's efforts to map the space of cultural practices out of such disparate data as the food people eat, the music they listen to, the magazines they read, or the sports they practice.

\subsection{From polities on paper to the space of polities}

Even though Bourdieu himself never ventured into full-fledged cross-national comparisons, such comparisons are always implicit in his work. For instance, he rejected as "substantialist" critiques that dismissed his indicators of "distinction" (e.g. going to a museum or listening to opera) as irrelevant in the U.S. context. His relational model, he argued, does not presuppose in any way that it is the same lifestyle practices that will establish social distinction in France and in America (e.g. 1998,1-3). He made a similar point in a telling side comment about poor women's voting patterns in France and Japan (1998, 4):

"In Japan, the rate of participation in general elections is highest among the least educated women of rural districts, whereas in France, as I demonstrated in an analysis of non-response to opinion polls, the rate of non-response - and of indifference to politics - is especially high among women and among the least educated and most economically and socially dispossessed. This is an example of a false difference that conceals a real one: the apathy associated with dispossession of the means of production of political opinions, which is expressed in France as simple absenteeism, translates, in the case of Japan as a sort of apolitical participation."

Ultimately, determining which practices create social differences, and in which way, is always context-dependent. We can only reveal them exposing the "principles of objective differentiation" at work in each particular social space. In fact, the only assumption that is necessary to the theory is the notion that every society is a society of difference. But different societies will always have different principles of social differentiation. In socialist societies, for instance, cultural and political capital may have played a proportionately bigger role than in non-socialist societies because economic capital is "officially out of bounds." (Bourdieu, 1998, p. 16)

To sum up, we take as our object the relationship between two structures: the structure given by the relations among the political practices found in each particular country and the structure given by the relative positions of states. Within a social space or field, a position is defined "by a system of relevant (meaning efficient) properties that allow it to be situated in relation to all others in the structure of global distribution of properties" (Bourdieu, 1996: 231). Different position-takings, such as acts of political volition (petition-signing, demonstrations, voting), associational memberships, volunteer activity or even, as others have shown, the simple ability to express one's opinion when queried (Jepperson, 1993; Bourdieu, 1984, 1993; Laurison, 2015), correspond to different positions in social space. But different political formations also have different "rules of the game" relative to the production of opinions as a form of political competence (Bourdieu, 1984; Herbst, 1992) or to participation in activist politics. Political competence and political dispositions (or the cognitive, emotive, perceptual and action schemas through which people relate to politics, and which are themselves structured by the social worlds they are a part of-see Bourdieu, 2000:155) thus mediate between the space of positions and that of position-takings (i.e., political opinions and political practices). For example, countries like Sweden, Finland, and Iceland occupy similar positions within a space of polities. This is largely due to their broadly similar institutional properties. Correspondingly, on average, respondents from those countries tend to take political positions that reflect the institutional properties of their country and that are opposed to the position-takings of, for instance, Russian or Hungarian respondents (countries that have much more strongly "statist" traditions).

What this suggests for us is that the objective differences observed in the structure of the national political spaces, and beyond in the space of polities, are homologically related to subjective differences in the actual experience, socialization, and representation - in short, the culture - of politics. Different practices and strategies will appear more or less doable, thinkable, or emotionally meaningful (Almond \& Verba, 1963; Emirbayer \& Goldberg, 2005) both across different national political spaces and within each national space depending on the institutionalized relational configuration of practices, strategies and movements. Hence we may not simply relate the well-documented differences in the strategies and practices of strikers in France and the United States (Friedman, 1988) to differences in the institutional or resource environment strikers face, but, more fundamentally and phenomenologically, to their culturally different relation to politics and claimsmaking as expressed in the broader structure of each of these countries' political "space."

\section{The space of polities in practice: an empirical illustration}

\subsection{Data and methods}

We use data from the World Values Survey (henceforth WVS) to conduct a relational analysis of political practices. Simply put, we want to determine which practices appear closely related to one another and which ones appear to be distant from one another (that is, in terms of the people who carry out these practices and the countries in which they are represented).

The dataset obviously constrains the things we can examine: the WVS contains information about individuals' membership and participation in associations, demonstrations, strikes, petitions, boycotts and building occupations. This is quite a broad range of data. However, the dataset is strongly biased toward the cultural repertoire of the Western social 
Table 1

Frequencies of different forms of political activity, selected countries, WVS.

Percentage of citizens who have participated in the following. . .

\begin{tabular}{|c|c|c|c|c|c|c|c|}
\hline Country & Petition & Boycott & Demonstration & Strike & Occupation & Association member & Association volunteer \\
\hline Argentina & 22.76 & 1.97 & 13.33 & 5.24 & 1.88 & 28.75 & 15.47 \\
\hline Austria & 56.07 & 9.69 & 16 & 2.32 & 0.75 & 51.58 & 24.05 \\
\hline Belgium & 71.77 & 12.13 & 39.9 & 8.7 & 5.89 & 54.08 & 28.92 \\
\hline Belarus & 8.77 & 4.14 & 16.26 & 1.06 & 0.63 & 8.5 & 10.7 \\
\hline Canada & 74.12 & 19.0 & 19.66 & 7.41 & 2.83 & 61.06 & 39.56 \\
\hline Chile & 19.48 & 4.99 & 15.67 & 8.71 & 4.16 & 36.92 & 33.08 \\
\hline Czech Rep. & 58.4 & 9.03 & 27.6 & 10.37 & 0.82 & 46.75 & 27.25 \\
\hline Denmark & 56.78 & 24.87 & 29.33 & 22.22 & 2.82 & 61.58 & 30.6 \\
\hline Finland & 50.76 & 15.2 & 14.78 & 2.5 & 0.1 & 53.66 & 31.98 \\
\hline France & 67.98 & 12.96 & 39.4 & 12.75 & 9.28 & 32.38 & 20.8 \\
\hline Hungary & 15.85 & 2.86 & 4.9 & 0.94 & 0.52 & 15.0 & 10.4 \\
\hline Ireland & 60.65 & 8.47 & 21.89 & 6.35 & 2.06 & 46.44 & 26.48 \\
\hline Italy & 54.62 & 10.32 & 34.78 & 5.37 & 8.03 & 33.65 & 21.05 \\
\hline Japan & 63.21 & 8.41 & 12.89 & 2.67 & 0.09 & 33.48 & 13.95 \\
\hline Luxembourg & 52.69 & 9.07 & 30.27 & 7.32 & 1.58 & 52.85 & 28.32 \\
\hline Mexico & 19.1 & 2.41 & 4.21 & 2.54 & 2.14 & 32.83 & 27.82 \\
\hline Netherlands & 61.44 & 21.88 & 32.3 & 4.59 & 5.39 & 88.04 & 43.57 \\
\hline Peru & 22.4 & 7.75 & 17.04 & 3.98 & 1.7 & 39.57 & 31.71 \\
\hline Philippines & 10.56 & 5.13 & 6.78 & 2.34 & 0.76 & 41.5 & 41.67 \\
\hline Poland & 21.13 & 4.34 & 8.81 & 4.61 & 3.04 & 13.52 & 8.86 \\
\hline Portugal & 26.94 & 5.74 & 16.99 & 3.55 & 1.36 & 20.4 & 11.8 \\
\hline Romania & 10.72 & 1.89 & 14.82 & 1.16 & 0.49 & 10.03 & 7.42 \\
\hline Russian Fed. & 11.69 & 2.49 & 23.91 & 1.55 & 0.65 & 9.12 & 3.92 \\
\hline Slovakia & 59.64 & 4.25 & 14.45 & 2.3 & 0.91 & 46.13 & 38.99 \\
\hline South Africa & 26.55 & 13.58 & 13.52 & 6.13 & 2.66 & 46.6 & 30.83 \\
\hline Spain & 27.41 & 5.76 & 26.42 & 8.15 & 2.69 & 22.37 & 12.79 \\
\hline Sweden & 87.27 & 33.97 & 35.84 & 4.6 & 2.95 & 72.41 & 40.1 \\
\hline Turkey & 15.21 & 6.31 & 7.54 & 2.16 & 0.66 & 5.56 & 4.81 \\
\hline Ukraine & 13.93 & 4.91 & 18.32 & 4.47 & 0.74 & 12.55 & 7.03 \\
\hline Great Britain & 80.71 & 16.56 & 13.33 & 8.6 & 2.1 & 27.1 & 41.9 \\
\hline United States & 81.32 & 24.87 & 20.75 & 5.84 & 4.13 & 79.25 & 55.17 \\
\hline W. Germany & 47.0 & 10.19 & 21.72 & 1.66 & 0.82 & 41.27 & 16.1 \\
\hline E. Germany & 62.3 & 6.35 & 46.82 & 1.85 & 1.2 & 29.23 & 12.11 \\
\hline Average & 31.95 & 9.64 & 17.65 & 4.7 & 2.49 & 37.91 & 25.83 \\
\hline
\end{tabular}

(in bold: highest and lowest scores)

movement as it crystallized between 1800 and 1900, while overlooking many types of political activity that could be of interest: voting, going to political rallies, or participating in more violent actions (e.g. joining militias, participating in acts of sabotage or terrorism).

For all its shortcomings, however, the WVS possesses an amazing strength: its cross-national character. This allows us both to expand our theoretical ambitions and go beyond Bourdieu's use of geometric data analysis to show the method's usefulness for thinking comparatively. Because the WVS is a rather crude instrument for carrying out this kind of analysis, whenever possible, we supplement it with references to more elaborate ethnographic and historical accounts of the polities we discuss. The fourth wave of the World Values Survey, conducted from 2000 to 2004, asks a broad range of questions regarding political participation in more than 70 countries. We focus on middle- and high-income countries. After removing additional cases due to missing or unavailable data, our final sample includes the 33 countries listed in Table $1{ }^{1}$

The main advantage of the survey is its remarkable breadth, which owes a lot to its principal investigator's ambition of mapping cultural change in societies across the world (See Inglehart, 1990, 1997; Inglehart \& Baker, 2000; Inglehart \& Welzel, 2005). Its main shortcoming is the near-identification of culture with values and feelings, which runs into the delicate problem of comparing subjective representations across cultural contexts. As MacIntyre (1971, 173-4) famously stated: "We

\footnotetext{
${ }^{1}$ In addition to countries that had missing data in the WVS (e.g. Singapore and South Korea), we also eliminated some of the smaller countries on which historical information, which we use to enrich our analysis, was difficult to gather (e.g. Baltic states). Also, we removed Greece because it was an outlier on several variables (however, doing so did not affect the general pattern of our results).
} 
cannot hope to compare an Italian's attitude to his government's acts with an Englishman's in respect of the pride each takes; any comparison would have to begin from the different range of virtues and emotions incorporated in the different social institutions."

For this reason, we focus our analysis on the few questions that are directly concerned with people's reported behavior (e.g., "Have you ever attended a street demonstration?" "Have you ever signed a petition?"). Such questions are arguably better suited to construct valid and reliable measures in a cross-national and multi-lingual survey than questions about personal views and attitudes. Furthermore, practices can always be taken to index systems of representations and dispositions. In other words, people's political practices (and non-practices) constitute the emergent form of their political habitus. To quote MacIntyre (1971,173-74) again: "It is an obvious truism that no institution or practice is what it is, or does what it does, independently of what anyone whatsoever thinks or feels about it. For institutions and practices are always partially, even if to differing degrees, constituted by what certain people think and feel about them." To be sure, surveys are no better able to capture the different phenomenological qualities of similarly named practices across nations (e.g. voting) as they are at capturing the different meaning of similar phrases and stated representations (e.g. trust in the legal system, or the police). Still, practices are more easily measurable: people are likely to know whether they have gone to the polls and cast a vote in the last election. By contrast, rating one's trust in the legal system, for example, not only requires a different kind of political competence but also supposes that individuals' implicit rating systems are commensurable, both within and across nations.

Next, we provide a description of multivariate relationships in our data by mapping out the space of political practices both across and within societies. To accomplish this, we employ principal components analysis (PCA), as well as multiple correspondence analysis (MCA). These techniques are analogous in that they involve the reduction of complex multivariate relationships into a smaller number of dimensions in a manner that highlights the structure of relationships among variables or categories (Greenacre \& Blasius, 2006; Harcourt, 2002; Le Roux \& Rouanet, 2005; Tabachnick \& Fidell, 2007).

Despite some differences in terminology, MCA and PCA are quite similar (Greenacre \& Blasius, 2006). For instance, the coordinates of an MCA can be interpreted analogously to the loadings of a PCA. However, MCA is rooted in the analysis of categorical data; it is appropriate for the analysis of individual-level discrete behaviors (e.g., Have you signed a petition?) or ordinal data that may have highly non-linear effects and are therefore better treated as distinct categories. MCA is of particular interest in our within-country analyses of political behavior, as we observe complex relations that are not easily reducible to linear patterns.

A significant advantage of both methods is that the two different structures can be represented spatially. This is often done through the use of bi-plots, which map not only component factor loadings (or MCA "coordinates") but also the relative location of cases within our data on those same dimensions. For example we can visualize the relationship between states and between political practices or membership in organizations. Bourdieu (1984) represents together a social space (e.g. demographic characteristics) and a cultural space (e.g. lifestyle practices). This greatly enhances the interpretability of factor scores and provides richer description for the purposes of inductive analysis. Finally, we contextualize our geometric data analyses with comparative case studies of several different polities. This allows us not only to go deeper into our interpretations but also to check them for consistency with what we know from detailed historical and ethnographic case and comparative studies conducted by others.

Our combined use of the MCA and PCA also departs to varying degrees from previous efforts to map cross-national patterns of political attitudes and behavior, such as Inglehart's factor-analytic approach (Inglehart, 1997, Inglehart \& Baker, 2000) or more recent efforts that combine factor analysis with regression (Bonikowski, 2010) or employ Fuzzy Sets (Bail 2008). Inglehart's efforts center on demonstrating that individual attitudes vary with country and level of development, and that patterns of cross-national differences map onto known or suspected cultural differences among nations (e.g., Protestant versus Catholic versus Confucian). Factor analysis flows naturally from Inglehart's vision of a latent construct (e.g. postmaterialism) that underlying individual attitudes and societal differences. ${ }^{2}$ Bonikowski (2010) goes beyond this, using regression analysis of relational predictors to explain patterns of cultural similarity. Bonikowski's study shares our interest in relationalism (among countries; not at the level of individual practices) and an emphasis on the historical patterns (e.g. imperial history) that may generate meaningful institutional and cultural configurations. Indeed, one might explain some of our observed societal differences with similar regression methods. Bail (2008) provides another intriguing alternative rooted in fuzzy-set analysis that in some ways falls closer to the spirit of our enterprise, as it is more focused on configurations of meaning (though again there is no attempt to link cross-national variation with intra-national patterns). Set-theoretic tools provide an alternative to traditional linear analyses that are particularly suited to identifying complex configurations, and represent a plausible alternative to our approach (if one has sufficient prior theory and knowledge to guide calibration of set membership).

Rather than aspiring to cluster or predict country cultural differences based on attitudes, this study instead interrogates country differences via a relational analysis of national-level political practices to better understand the meaning of societal differences. Our primary goal is both inductive and theoretical: by locating countries on a "map," we argue, we are better able to produce the analytical constructs that will guide and organize our interpretation of cross-national patterns.

\footnotetext{
${ }^{2}$ PCA and MCA are not anchored in the notion of latent variables, but simply reduce multivariate data to a small number of dimensions while maximizing explained variation.
} 


\subsection{Measures}

Measures of individual-level political practices were used in two ways. First, we aggregated the data at the national level computing country means - to explore the varying structure of polities via PCA. Later, we analyze the individual-level measures themselves in within-country MCA.

Total membership in voluntary associations (Member). The WVS includes a series of questions to determine whether individuals belong to associations of various types, including "political associations," "religious groups," and so on. We summed these dichotomous measures to yield a count of different types of associations to which an individual belongs. We used country means in the aggregate analyses. Our MCA plots use discrete categories of zero, one, two, and three or more memberships. We collapsed higher values to reduce clutter on the MCA biplots.

Working for voluntary associations (Volunteer). The WVS also includes items identifying whether individuals do "unpaid work" for voluntary associations of various types (what Curtis, Baer, and Grabb (2001) refer to as "working memberships"). We constructed aggregate PCA measures and MCA categories for volunteering in the same manner as membership, above.

Participation in demonstrations (Demonstrate), participation in strikes (Strike), participation in boycotts (Boycott), occupying buildings (Occupy), and signing petitions (Petition). The WVS identifies respondents who have "actually done" each type of activity. It also inquires about attitudes, distinguishing those who "might do" the activity versus those who "would never" do such a thing. Aggregate analyses examine the country proportion of individuals who have "actually done" each activity, versus all others. MCA plots examine the full range of WVS categories.

We include additional individual-level demographic measures as supplementary variables in MCA plots:

Gender. Coded dichotomously (male $=1$, female $=0$ ).

Education. Coded ordinally, as highest level of education completed. To reduce clutter in the MCA plots, we reduced this to three categories: primary degree or less; some secondary or a secondary degree, and those with at least some tertiary education.

Religiosity. Coded ordinally, from 0 to 3. Zero indicates religion is “Not At All Important”, 1 "Not Very Important”, 2 “Rather Important" and 3 "Very Important".

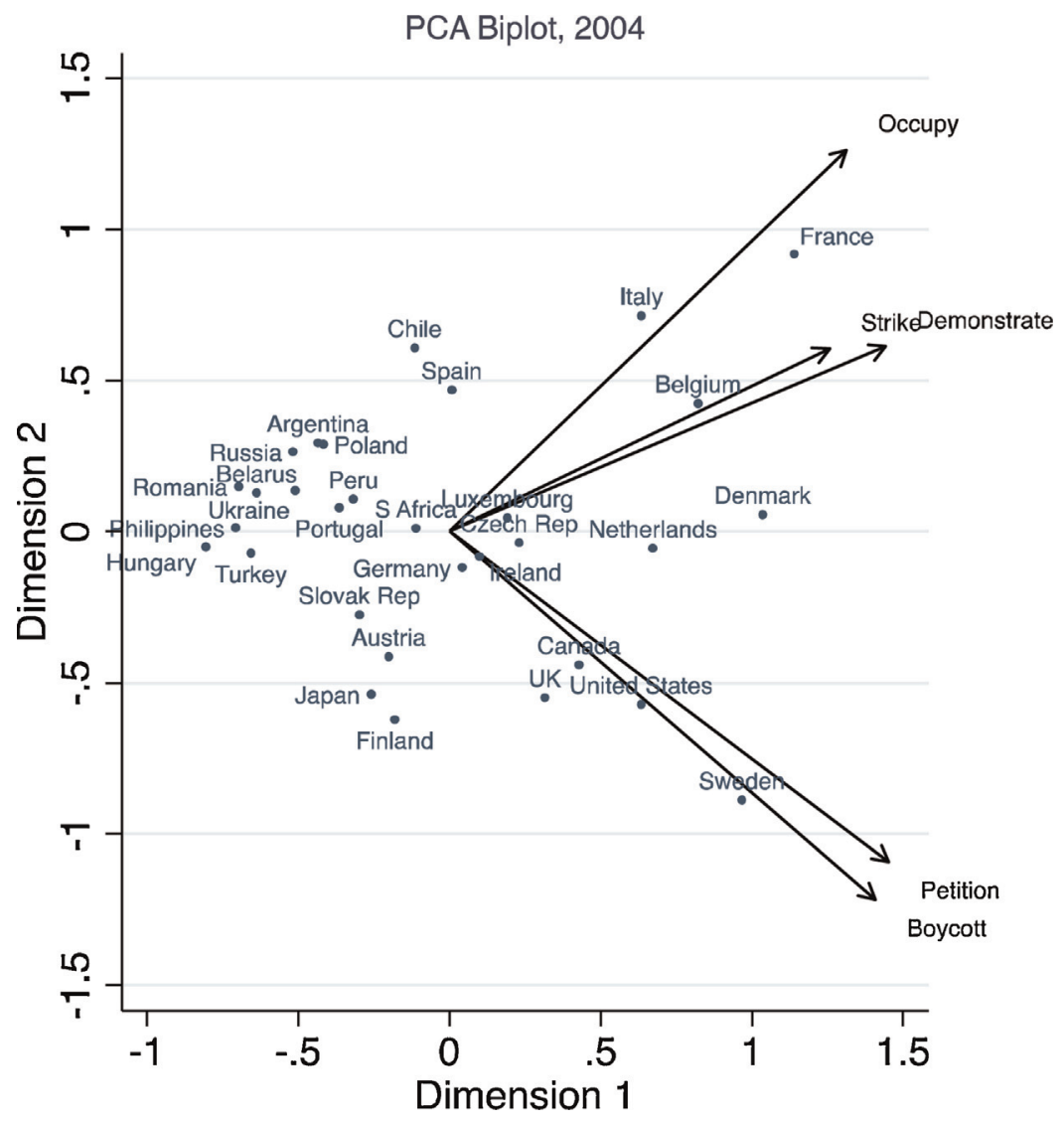

Fig. 1. Biplot of political practices, Factors 1 and 2. 


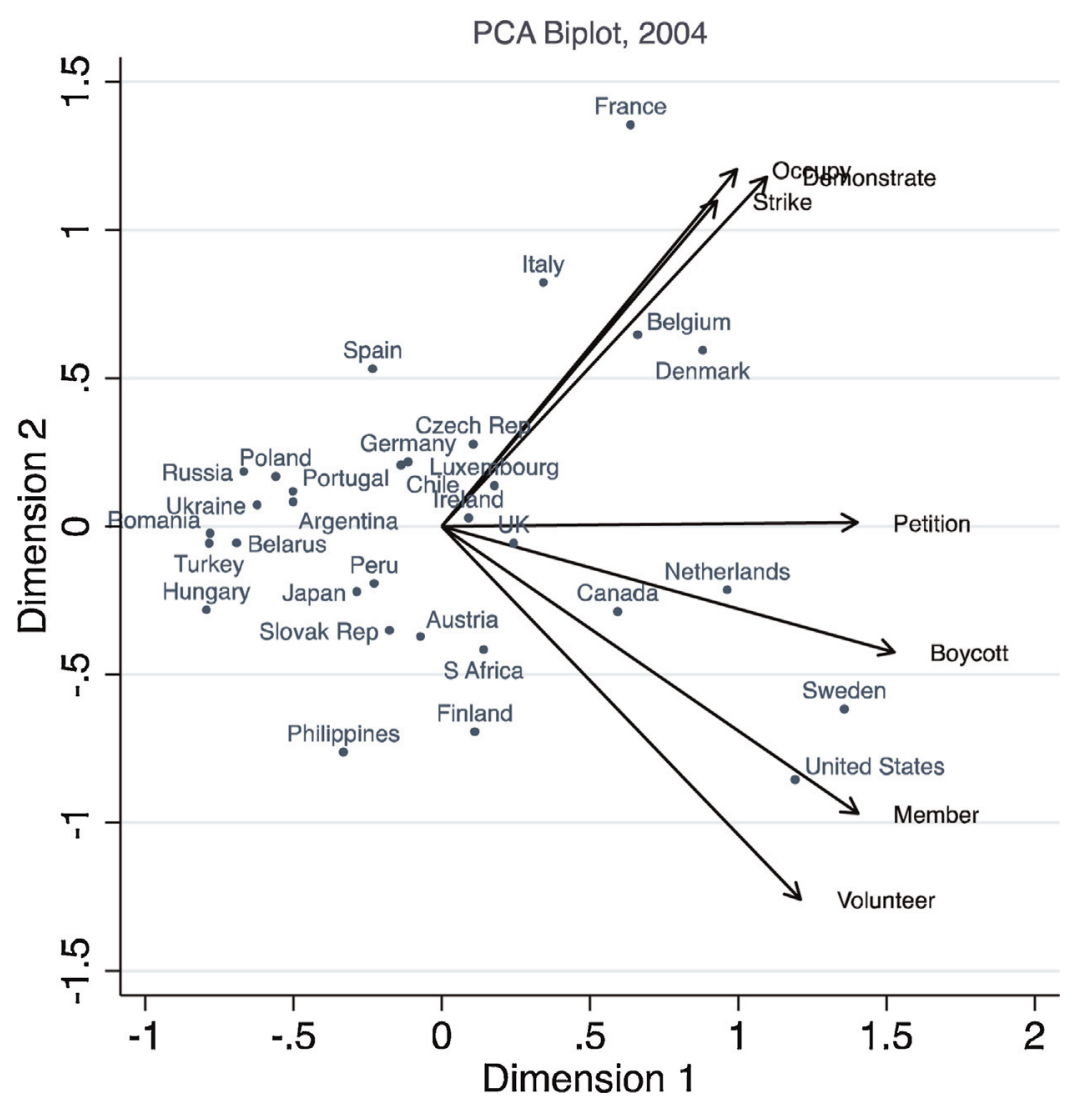

Fig. 2. Biplot of political practices, with membership and volunteering, Factors 1 and 2.

\section{4. "Doing politics" across countries}

Our first empirical task is to describe how countries fall vis-à-vis one another in terms of the political practices of their citizens (what we call here the "space of polities"). Table 1 offers a summary of the main cross-national variations in a range of political practices for a group of countries selected from the World Values Survey. Countries exhibit very sharp differences. For instance, the highest frequency for street demonstrations and building occupations occurs in France (39\% and 9\%, respectively); but these practices remain much more rare in Finland (15\% and $0.1 \%$ ). Similarly, the percentage of citizens who have ever signed a petition varies, for instance, from less than $6 \%$ in Turkey to over $87 \%$ in Sweden; even a country where the return of democracy occurred some 40 years ago, Spain, still stands barely over $27 \%$.

The principal component analysis presented in Figs. 1 and 2 helps us elaborate the cross-national differences much further. Fig. 1 represents the space of five basic political practices, overlaid with the space of polities. ${ }^{3}$ In this first figure, practices related to association-joining (membership in voluntary associations and work in those associations) are not included. Fig. 2, by contrast, is based on the same data but the two associational variables are now active-that is, they participate actively in the determination of the space.

\subsection{The volume and temporal structure of political action as organizing dimensions}

The two figures show a basic opposition between the "doers," on the right hand side of the map, and the "non-doers", or at least less active polities on the left, which are not associated with any type of political activity and represent - by far - the bulk of the countries included in this analysis. Most of the Eastern and central European countries (e.g. Hungary, the Russian Federation, Ukraine, etc... ) and Latin American nations (Mexico and especially Argentina), as well as some Western European nations like Portugal, are found in the latter category, while the United States, Sweden and the Netherlands are the

\footnotetext{
${ }^{3}$ The Fig. 1 biplot is based on country averages calculated from responses of 81,826 individuals. Later figures have slightly fewer cases due to the inclusion of additional variables, which are missing for some individuals.
} 
three countries with the highest proportions of people who have been involved in the categories of activities surveyed in the WVS. The second factor opposes the countries whose citizens focus comparatively more on membership activities (Sweden, US, Canada) to those whose citizens "do politics" mainly through means of episodic types of action. Keeping with the Bourdieuian conceptual language, a simple way to interpret these patterns is to point out that while the first dimension captures the relative volume of political action, the second dimension focuses on the structure of this action in terms of the time involvement required. Contributing most to Factor 2 are the volunteering variable, on the one hand, and the street demonstrations, building occupations and strikes variables, on the other. The United States and France exemplify the polar opposition. In the US, volunteering is common while contentious actions are not. Conversely, in France, participation centers on forms of action that reflect a pattern of intermittent outbursts rather than one of long-term, repeated commitment. Boycotts and petitions, interestingly, fall where we may expect them on this temporal continuum, with boycotts (which require repeated action) being closer to the membership and work variables and petitions contributing nothing on Factor 2 once the associational variables are taken into account.

Time, then, appears to be a key dimension that organizes the practice of politics across nations. In the space of polities, countries differ from one another first in terms of how much time their citizens devote to political activities (with the majority devoting almost no time at all), and second, in terms of the rhythm of their time commitments to politics - i.e. whether those citizens who are active act in a manner that is regular and repeated, as opposed to episodic and concentrated. Three broad ensembles of countries thus emerge from the analysis. First are the countries that are low on Factor 1; they have a fairly "inactive" citizenry (at least from the point of view of the practices surveyed in the World Values Survey). These countries are clustered on the left-hand side of Fig. 1. The second set, in the upper right quadrant of the graph, comprises the polities that have a relatively "active" citizenry (high on Factor 1) but relatively more episodic time commitments (high on Factor 2). A third group consists of the polities that have a more "active" citizenry (high on Factor 1) but have relatively more stable and repeated time commitments (low on Factor 2); these are clustered in the lower right quadrant.

\subsection{Interpreting the time structure: polity integration and stateness}

Until now we have not said much about the underlying political structures that may lie beneath these political patterns. The neo-institutionalist literature in sociology helps provide some clarification. Jepperson (1993: 91,2002) describes those countries that are low on Factor 1 in our analysis (i.e. our "less active" polities) as "poorly integrated politically," while Jepperson and Meyer (1991:216) refer to them as "segmental" polities. Even though most of these states are now functioning democracies - and some have even been democratic for several decades - they share a fairly recent authoritarian past. The majority of them, indeed, fall into two clearly identifiable categories: 1) vassal states with a long history of subjugation to a strong external rule (Hungary, Belarus, Ukraine and Poland for the last two centuries); and 2) former imperial powers that were ruled militarily from above in the pursuit of "autarchy and dictatorial modernization" (Derluguian, 2007, 5) throughout much of the twentieth century. Russia, Turkey, and Portugal are canonical examples of this second path. Indeed, these states were often just as brutal vis-à-vis their own populations as they were vis-à-vis the populations of conquered territories.

In both types of societies, rebellion against the center carried very tangible risks for the people who got involved and almost always ended in failure. The case of Hungary, the lowest country on Factor 1, offers a striking illustration of this point. Unlike many other states, including neighbors like Poland, Hungary "did not experience a truly successful revolution" in the modern era. To the contrary, nationalist and revolutionary hopes and impulses were repeatedly crushed, so that the country has had "very few positive experiences" to build upon. The uprising in 1848, the post-1918 revolutions and the 1956 revolt all failed, sometimes in a quite catastrophic manner (Seleny, 1999, 504-05). Contemporary scholarship on Hungary characterizes the society as politically "quiescent," rather disengaged, and pragmatically oriented toward elite consensus and bargaining in spite of high levels of political dissatisfaction (Seleny, 1999; Ekiert \& Kubik, 1998, 554-556; Hankiss, 1989). This diagnosis not only agrees with Hungary's location on Factor 1 in our data (the country is very low on every type of action) but also on Factor 2 (Hungary is positioned away from the more episodic/contentious types of political activities).

Hungary is located very close to Poland on the map of the space of polities. Yet while this proximity captures similarities in the two countries' paths into political modernity, Poland's history was also distinctive in important ways. Poland especially contrasts with Hungary on Factor 2, that is, in terms of its level of contentious politics. This is not surprising since, as Seleny puts it, "by the end of the Second World War Hungarians and Poles had reasons to learn profoundly different lessons about the efficacy of open resistance and revolution." (1999:504) Compared to Hungary, Seleny continues, Poland had a much more successful history of rebellion: it emerged victorious in the Polish-Soviet war of 1920-1921. While the country suffered very heavy losses during World War II, it came out of it "free of the weight of collaboration and concomitant issues of moral complexity that burdened Hungary" (505) and found itself on the winning side when the Allies declared victory in 1945. Finally, after Poland turned to communism, the Soviet Union treated the country relatively leniently in comparison to other Eastern Bloc followers. The Poles interpreted this (whether correctly or not) as an acknowledgement of their reputation for open resistance and rebellion (Seleny, 1999, 505). From the standpoint of politically conditioning experiences, Poland indeed retained a lively political counterculture and an independent Church, even during the imposition of martial law.

Thus, even when we zoom in on a segment of the social space in question, we also find "self-similar" regularities (Abbott, 2001; Bourdieu, 1984; Lorrain \& White, 1971). As may be expected from the hypothesized effects of collective memory, Poland indeed exhibits the highest level of disruptive protest actions, especially by unions, against the state among the four post-communist nations studied by Seleny (1999). Polish society is marked by relatively "high levels of political 
mobilization, contentious party competition around several overlapping, deep ethical-ideological cleavages, relatively low levels of elite consensus, and a moralistic political discourse" (Seleny, 1999: 433).

Let us now turn to yet another country that is low on Factor 1. Like Hungary, Argentina also has a history of relative depoliticization, but it is a very different one. In Argentina, habits of public engagement avoidance actually go back to before twentieth century authoritarianism and its military control of practically all civilian institutions. As many accounts have suggested, because formal political participation was restricted to citizens, because the proportion of immigrants among the Argentinean population was very high, and finally because the procedure for naturalization was very cumbersome and thus rarely picked up, politics in nineteenth century Argentina took the shape of a game between local political factions that left the vast majority of the population indifferent (Rock, 1985; Sabato, 1992). This politico-demographic situation, combined with an oligarchic influence that was always acute even by Latin American standards (Collier \& Collier, 1991:129-131), forged a form of citizenship that was somewhat more alienated than elsewhere on the continent.

What these examples suggest is that political habits might reproduce themselves through their inscription, first, in the political structure itself and, second, in the memory of past events embodied in people and institutions and passed on through interpersonal interactions and formal and informal socialization (Tilly, 2008). Thus, Howard (2002) finds in his "experiential approach to societal continuity and change" that the legacy of communism (which, as we have shown in the Hungarian case, often extends back further to an authoritarian pre-communist past) explains in large part the "collective non-participation" habits of some Eastern European citizenries, as well as their low levels of societal trust in general. Having been forced to join all sorts of organizations during communist times, citizens in post-communist European nations were eager not to join any in democratic times. Instead, they chose to continue, instead, to rely on the informal networks that had played such a critical role in helping them get by earlier.

Experiential aspects also explain political patterns at the other end of the continuum captured by Factor 1 . We find two types of countries on the side of the "active polities," and they are quite different, depending mainly on their position on

(a)

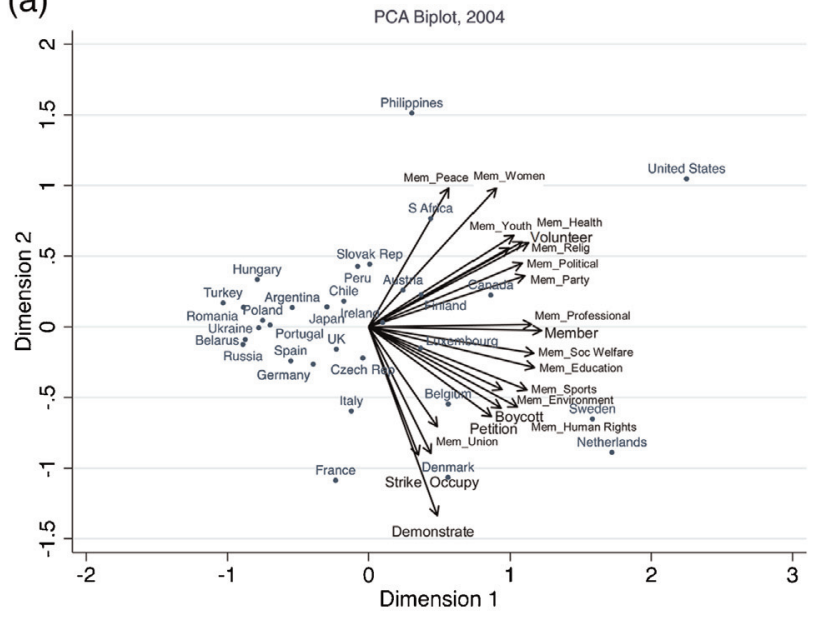

(b)

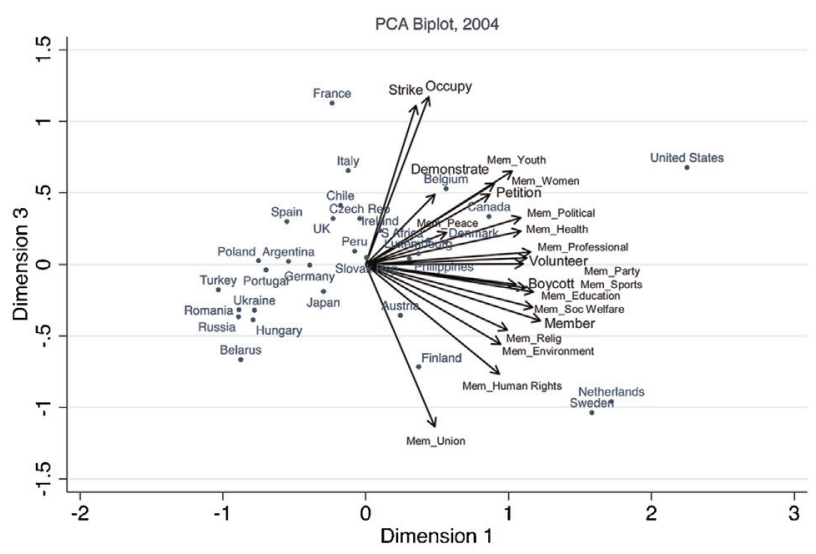

(c)

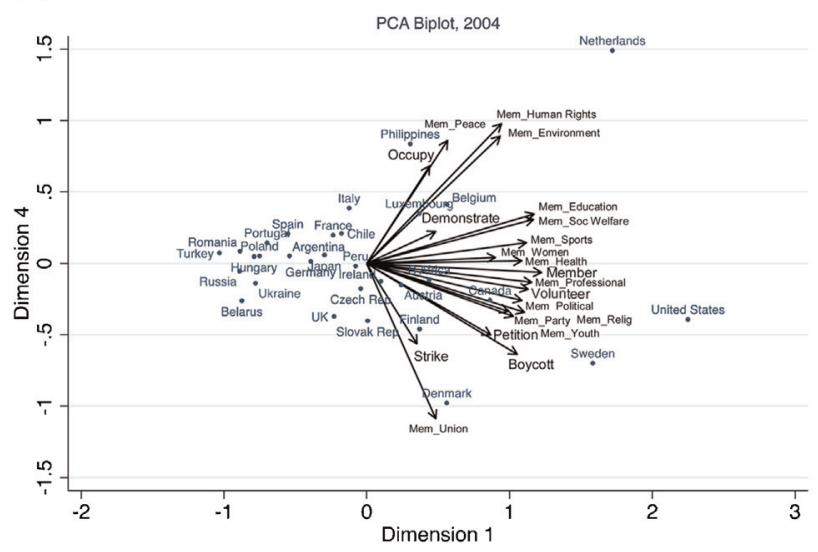

Fig. 3. (a) Biplot of all political practices, including association types, Factors 1 and 2. (b) Biplot of all political practices, including association types, Factors 1 and 3. (c) Biplot of all political practices, including association types, Factors 1 and 4. 


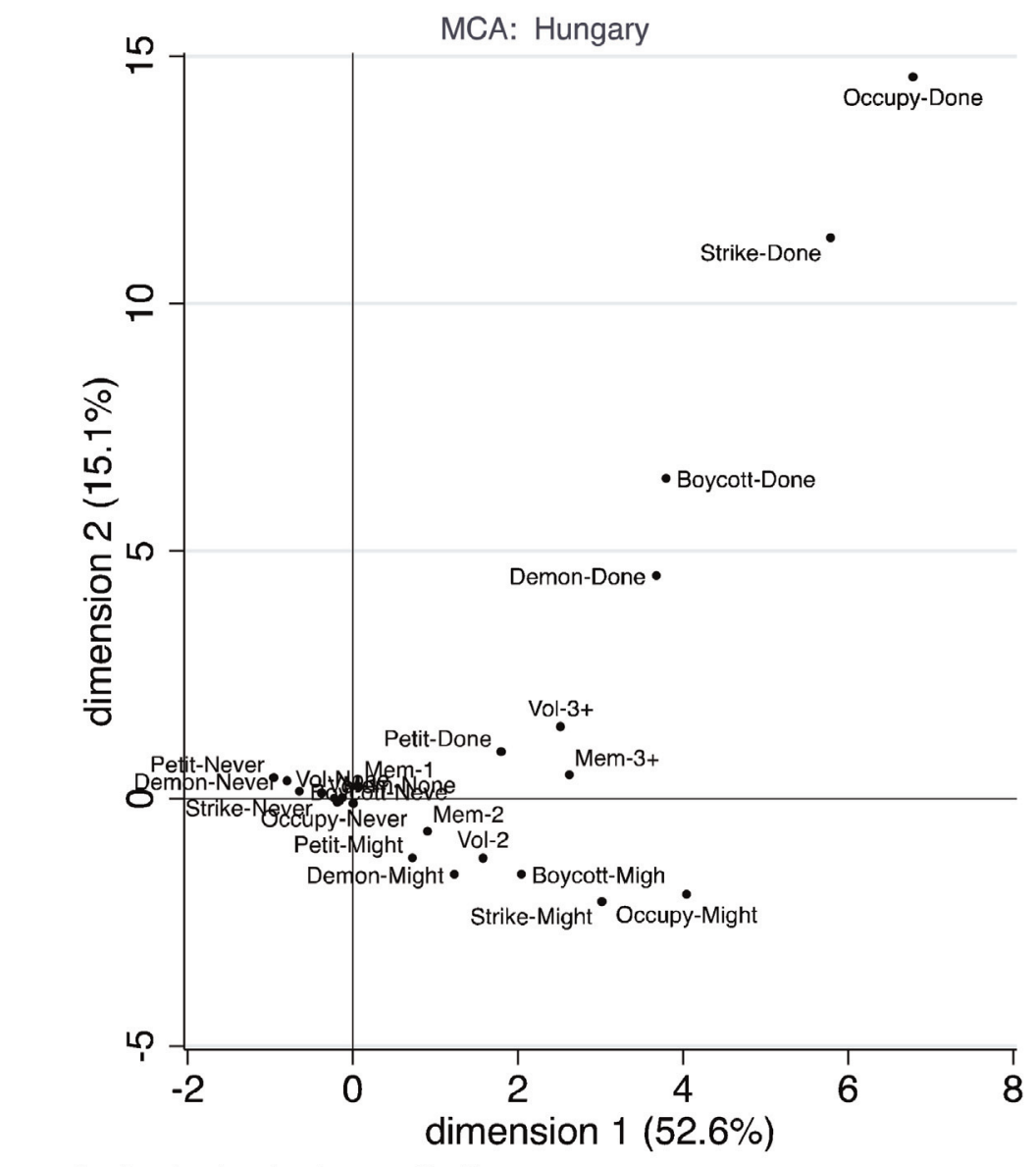

coordinates in standard normalization

Fig. 4. Multiple correspondence analysis, Hungary 2000-2004.

Factor 2. We have already seen that France stands highest on political contention measures (Fig. 1). Again, history is key here. If anything, three major successful revolutions between 1789 and 1848 , and a succession of efficacious contentious episodes since then have taught the French that "taking to the streets" often works: political power either falls, or it responds under pressure. In this country, various forms of "disruptive" action (e.g. demonstrations, building occupations, even strikes) may thus be understood as a more natural route to political socialization than, for instance, joining a voluntary association. The underlying reason for such a pattern of political participation must be found in the political structure itself. France has been dubbed the ideal-typical "statist" nation (Birnbaum \& Badie, 1983; Dyson, 1980; Jepperson, 2002). The state has traditionally embodied the pursuit of rational progress in the name of society, but it remains fairly cut-off from society in its organization and practice: its mission, rather, is carried forward by a highly elitist bureaucracy that is accountable mostly to itself and often acts as an agent of social division, rather than cooperation (Kriesi, Koopmans, Duyvendak, \& Giugni, 1995; Ancelovici, 2008). Ongoing coordination and negotiation of societal claims, as in Sweden, or institutionalized pressure (through lobbying or the courts), as in the United States, are both unpractical and illegitimate. "The street," by contrast, is not only one of the few remaining avenues for channeling demands, it is also a well-recognized one. French governments have, for instance, a long history of acknowledging various disruptive groups - from striking public-sector employees to the disaffected youths of the suburbs - and, often, of settling disputes in terms that are favorable to them in "a continuous process of signaling, negotiation, and struggle" (Tilly, 1986; also see Friedman,1988).

France represents one extreme on Factor 2. The United States is its mirror image. Factor 2 opposes countries that "boycott" and "petition" (e.g. the US) to countries that "demonstrate", "occupy buildings" and "strike" (Fig. 1). But when associational variables are included in the model (Fig. 2), the temporal structure of the opposition becomes even more remarkable. Not only do Americans join a lot of associations, as de Tocqueville noticed long ago; they work more in them (the latter variable helps differentiate the United States from Sweden, for instance, in spite of the countries' proximity on other political dimensions). What this suggests is that the axis for Factor 2 may be read - with some qualifications - as the opposition along the statist-societal dimension identified by Jepperson (e.g., 2002): countries not only harbor quantitatively different 


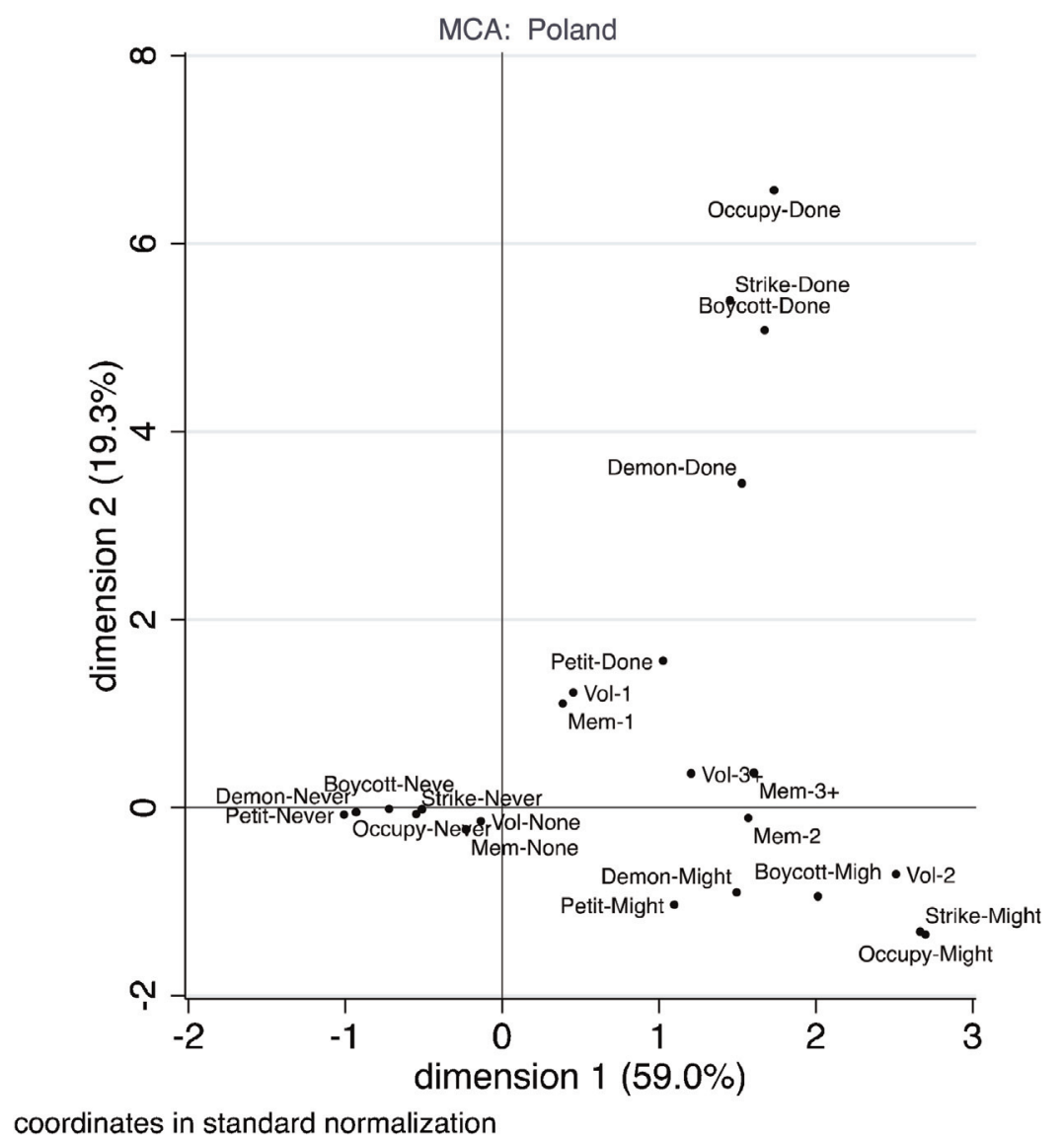

Fig. 5. Multiple correspondence analysis, Poland 2000-2004.

amounts of political activity, but they also have qualitatively different rhythms of political life, for clear historicalinstitutional reasons. In other words, the relative stateness of a polity might stand behind the time structure of its politics.

\subsection{Corporateness and the cultural meaning of associational forms}

Next we look at the disaggregated types of associations in which people worked and of which they were members. Fig. 3a simply presents the F1 (Factor-1) and F2 (Factor-2) projection on the basis of the added information. It shows, again, that the countries that are generally very active on all dimensions of action tend also to be associated with associational memberships of all kinds: religious, environmental and educational associations, unions, as well as sports associations. ${ }^{4}$ Although Factors 1 (volume) and 2 (time structure) represent, by far, the most important sources of cross-national variation in political practice, there is much to gain from a close-up analysis of Factors 3 and 4. Factor 3 (Fig. 3b) opposes the countries with high levels of union membership (most of them Scandinavian, plus Austria and the Netherlands) to countries with heavy strike and building-occupation activities (mostly France and Italy). This is not a paradox: the labor movement takes a different shape in different nations (Western, 1997): strikes along this dimension are associated with a specific union tradition, represented by the French-Italian model, which historically derives from anarcho-syndicalism and tends to rely on confrontational episodes and organizations. The fact that demonstrations are also strongly and positively associated with Factor 3 suggests that - in those countries well represented on the upper segment of the vertical axis, such as France, Italy, the United States and Belgium - demonstrations might be mainly associated with labor militancy. On the opposite end of Factor 3, we find countries characterized by more "corporate" forms of social organization, as defined by Jepperson (2002) and Schmitter (1974). Labor participation here is inscribed, fundamentally and phenomenologically, in a different mode of collective belonging, based on large membership organizations that are generally in charge of arbitraging conflicts. More generally, associational memberships in this context often mean the enactment of a role: they are an expression of corporate group belonging (e.g., workers) much more than a form of individual "choice" or a voluntary commitment. They therefore do

\footnotetext{
${ }^{4}$ Sporting associations are significantly politicized in some national/historical contexts and not in others. We opted to include them, but results are essentially identical if they are removed.
} 
not necessarily entail much "active" involvement and are not associated with high levels of volunteer work (Fourcade \& Schofer, forthcoming).

This difference really becomes apparent when we look at Factor 4 (Fig. 3c). Factor 4 does not account for much of the variance (8.14\%) but again, the pattern is interesting and interpretable. The main analytical interest of this fourth dimension is that it helps single out the Scandinavian countries, particularly Denmark and to a lesser extent Sweden, that strongly associate high levels of union membership with strikes (but not building occupations). As many commentators (e.g. EspingAndersen, 1990; Lipset, 1961) have suggested, Denmark indeed stands quite apart from the rest of the Scandinavian world, particularly in terms of the pugnacity of its labor movement.

\section{Comparing political spaces}

From an externalist point of view, a country is a point in the "space of polities," a location relative to other societies along the dimensions we have just identified and to which we have attributed definite meanings. The location of a country in multidimensional space characterizes a nation's political practices within the broad patterns of variation observed across societies. From an internalist perspective, however, a country is itself a differentiated space of political practices, a bundle of factor loadings that reflect the constellation of practices (and non-practices) observed therein. At the onset of this paper, we gave ourselves the task of describing the political spaces of individual countries and deriving from such examination insights into the meaning of different political practices in their context of performance. In Figs. 4-8, we provide, as illustrative examples, the first and second dimensions for five countries (Sweden, Hungary, Poland, United States and France), each of which represents a distinctive polity type in the space of polities.

The MCA suggest a number of conclusions: Hungary (Fig. 4) is the most distinctive country of all, in the sense that it is composed of a very homogeneous (politically speaking) population whose members are not very active (at the center of the map). To the extent that people participate in contentious politics, they engage mostly in relatively benign forms of claimsmaking (e.g., petitions). Furthermore, and in contrast with the other three countries, participants in "contentious" political activities in Hungary are very much outliers. Supplementary cluster analyses reveal that the most active of these participators are much younger than in other countries, suggesting important cohort effects. Importantly, and dovetailing on our earlier comparison between Hungary and Poland, the Polish "space of political practices" looks quite similar (Fig. 5). This is not

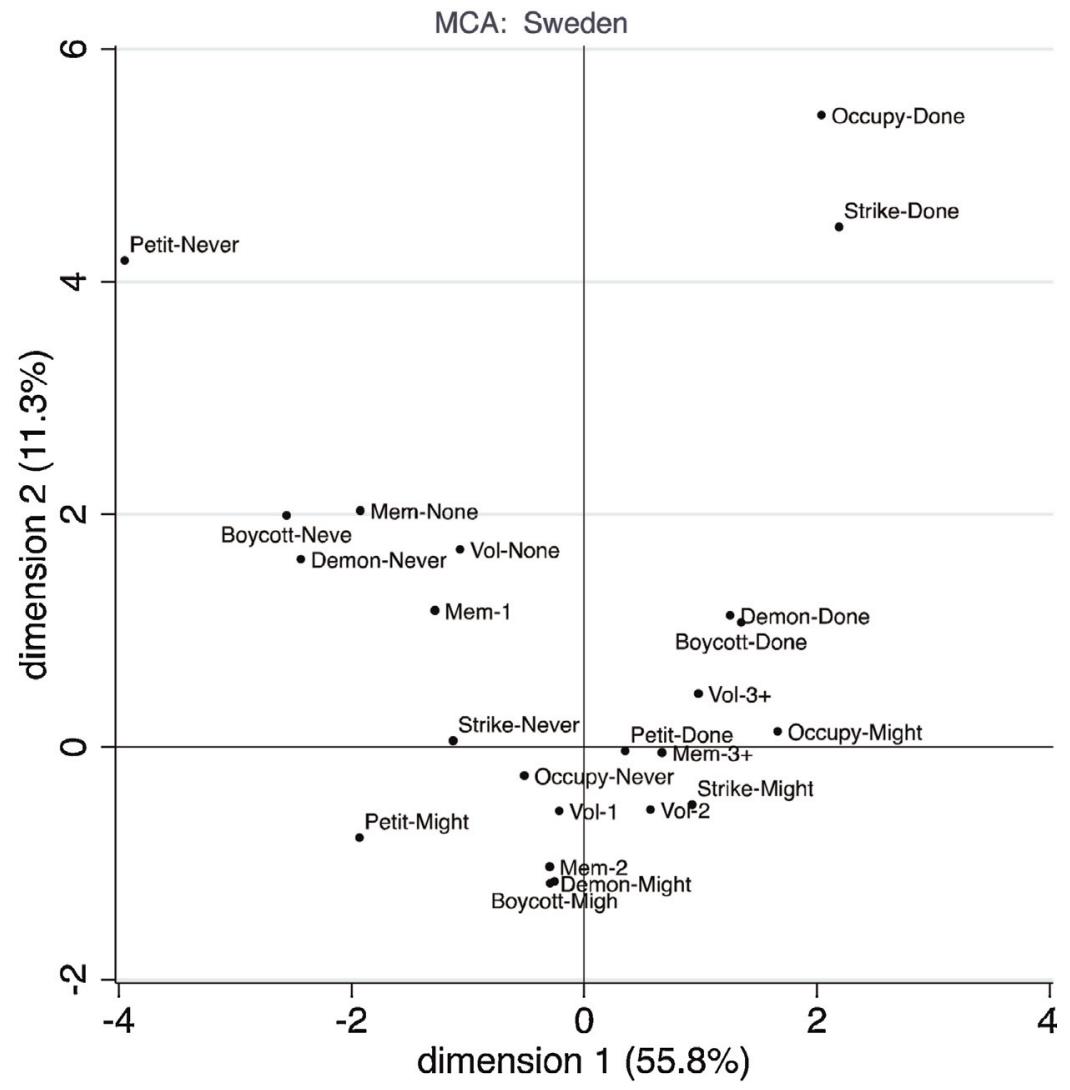

Fig. 6. Multiple correspondence analysis, Sweden 2000-2004. 


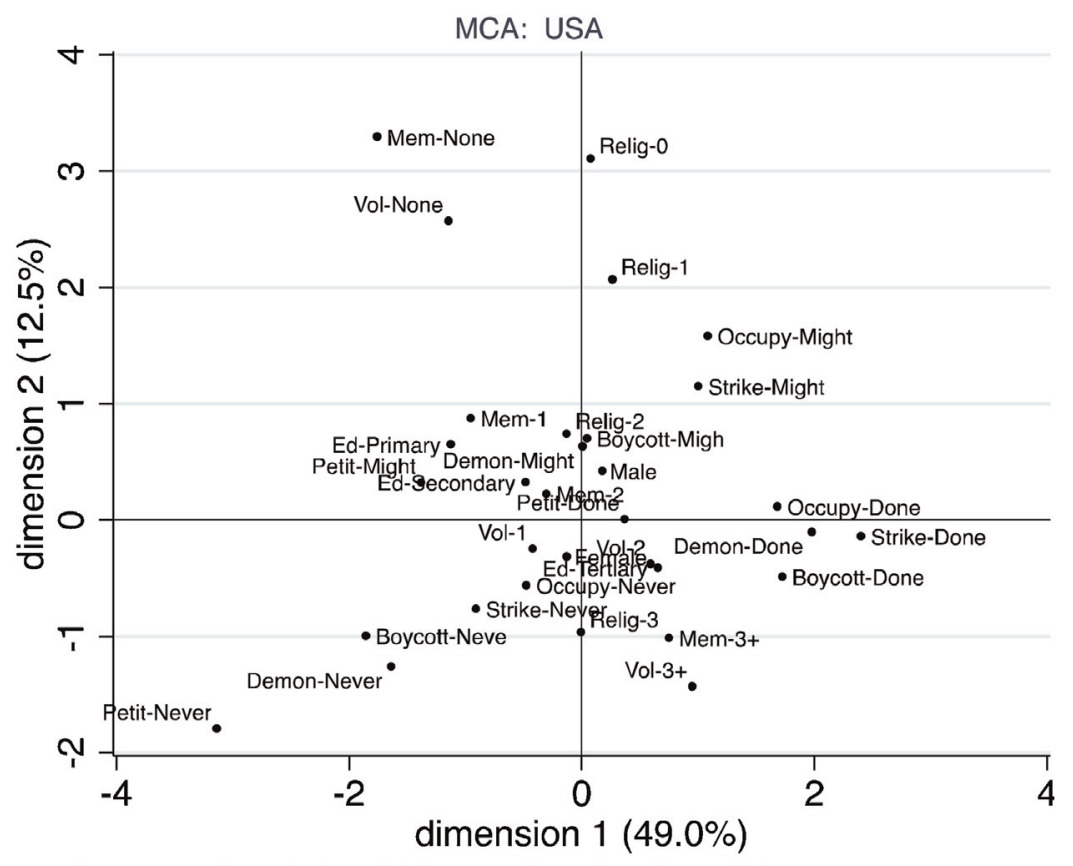

supplementary (passive) variables: gender education religion coordinates in standard normalization

Fig. 7. Multiple correspondence analysis, with supplementary variables (religiosity, education, gender): USA 2000-2004.

surprising: countries that look structurally similar in the within-country analyses will load together in the broad cross-national analysis.

In contrast to Hungary, the political spaces of the United States, Sweden and France are much more differentiated. However, the principles of this differentiation vary substantially across countries. For instance, in France (Fig. 8), high participation and membership in voluntary associations is associated with labor activity and generally with contentious political practices. In the United States (Fig. 7) and Sweden (Fig. 6), on the other hand, those who are highly involved in associations are substantively different people from those who carry out more contentious actions. For example, the US map shows nicely that people with high levels of membership and participation in voluntary associations are clustered much closer to the people who "would never do" the more contentious types of political actions than in France, where contentious action and associational memberships tend to overlap.

Interestingly, Sweden and the United States have similar structures of "non-participation" (top left corner of Figs. 6 and 7 , respectively). In France, on the other hand, there appears to be a greater disconnection between membership in associations and political participation: the non-members/non-workers in associations are an entirely separate group, whereas in the United States and Sweden they are closely associated with the "might dos."

Obviously these analyses are extremely partial and are only meant to illustrate the analytical usefulness of an approach conceived in relational terms. It is of course possible to refine the empirical toolkit much further and get an even greater purchase on the cases. One such strategy involves including more demographic data into the analysis, in order to assess whether the differences we observe in terms of practices also correspond to sociological differences in terms of the people who carry out these practices. We know these variables (education, income, marital status, gender, age, ethnicity, religiosity, etc.) matter across the board: people who are more educated, for instance, tend to participate more in politics. But they might matter differently across nations, as evidenced, for instance, by the different positioning of highly religious people vis-à-vis politics in the US and in France (Figs. 7 and 8, respectively): moderately (rel-2) and highly (rel-3) religious people in France are not active at all, whereas in the US they are more sympathetic toward contentious politics (prevalence of "might dos") and at least ambivalent toward it, as well as closer to the associationally active. A second strategy would be to analyze even more inductively how the population falls into categories of people sharing a common pattern of political activity, then analyze countries as varying constellations of these categories or clusters (see, e.g., Bail (2008) for such an approach using fuzzy-set analysis, or Bonikowski (2010) for a similar perspective using hierarchical cluster analysis). These strategies, however, might dilute the comparative edge we are seeking here by assuming correspondence among categories of individuals across countries.

\section{Conclusion: relation and structure}

Our first purpose in this paper has been to show the usefulness of a structural-relational approach, grounded in geometric data analysis, to generate insights into the understanding of cross-national variations in the practice of politics. The main 


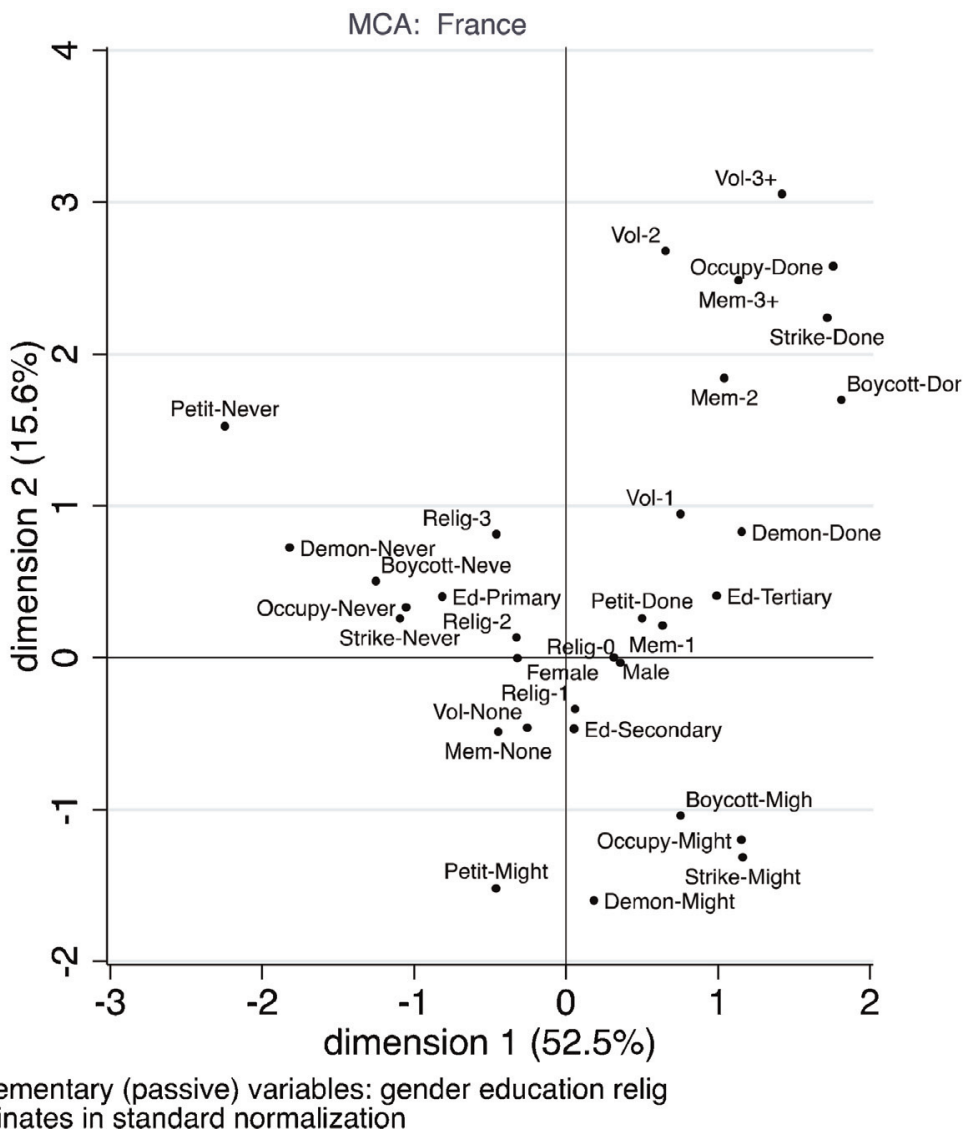

Fig. 8. Multiple correspondence analysis, with supplementary variables (religiosity, education, gender), France 2000-2004.

advantage of such an approach is that it takes the indexical quality of political practices seriously. What any individual practice "means" always depends in some sense on the context of use: who takes it up, when, within what kind of institutional field (Amable, 2003), and against which alternative and seemingly available practices (what Bourdieu, echoing Foucault, elsewhere (1993) calls "the space of possibles"). We use the term indexical not because we think that political practices are reducible to semantic analysis but to point out that, just like utterances take their meaning only when situated against a background of expectations and discursive contexts, political practices cannot and should not be limited to internalist readings.

Bourdieu's critique of substantialism was a natural starting point for this study. A naïvely substantialist analysis would treat political practices like strikes, demonstrations, boycotts, riots, voting, etc. as discrete and isolated forms, and, what is more, as if their meaning were given and indeed invariable. It would perform what Whitehead (1925) called "the fallacy of misplaced concreteness." Although this approach is quite common in the social sciences, it must be resisted. The political actors of different countries may take up a specific political practice (e.g. a protest action) for different reasons, with different temporal logics, and more or less intensity. In other words, when using terms like 'petitioning' to compare and contrast practices in different countries, we should be careful to not make "false friends" of the term by allowing "surface form to indicate probable meaning" (Enfield, 2010: 1). Relational analysis "is a reminder that comparison is possible only from system to system, and that the search for direct equivalences between features grasped in isolation, whether, appearing at first sight different, they prove to be 'functionally' or technically equivalent (like the drinks of Pernod in France and shôchû or saké in Japan) or nominally identical (the practices of golf in France and Japan, for instance), risks unduly identifying structurally different properties or wrongly distinguishing structurally identical properties" (Bourdieu, 1998: 6). Furthermore, by comparing "substitutable" practices vis-à-vis other practices within each polity (to obtain a "space of position takings"), and also comparing these spaces "system to system," we are compelled to adopt a resolutely inductive approach to the theorization of political difference. We ground it in the analysis of political space (an empirical construction) instead of politics on paper (an a priori one), and in the space of countries instead of countries on paper.

The space of political position-takings roughly corresponds to the social space as defined by the historical trajectories of the countries we have investigated (e.g. countries that experienced long and repeated periods of repression and domination by external powers or autocracies tend to have a "low volume" of political engagement as captured by the WVS) as well as 
their political institutions (e.g. the degrees of statism or corporatism within the political and bureaucratic fields). The secondary literature is precious here. It helps demonstrate that the experience of political life leads to the embodiment of political competencies that are quite different from country to country even if they generate, in the dialectic with objective political, economic, and social realities, similar regularities of political practice (e.g. the high volume of membership in associations is achieved according to different common-sense strategies and within different material realities in the U.S. and Sweden). Even configurations of political practices that may look superficially similar turn out to be organized according to quite different temporal logics. Thus, the French protest according to quite a different political rhythm than their counterparts in the U.S. Even the groups of people who protest in the U.S. look different than those in France who use similar strategies, indicating that comparing political practices such as protests, in and of themselves, is misleading.

\subsection{Structural relationalism versus interactional relationalism}

Importantly, and in contrast to the neo-institutionalist perspective (e.g. Meyer, Boli, \& Thomas, 1997), no country's pattern is explained, a priori, by a relationship of direct interaction with "world society," or by a political, economic or cultural relationship with another country. In other words, because the national patterns we are analyzing here are rooted in the behavior of individuals, we are eschewing the kind of relationalism that presupposes actual connections between empirical persons or institutions (in this case states). Rather, we have treated countries as epistemological entities defined by statistical properties that could be easily filled by any particular empirical country with more or less the same properties. As pointed out earlier, Bourdieu's (2005: 77) is a structural relationalism as opposed to an interactional one (De Nooy, 2003; Fourcade, 2007).

With that rhetorical precaution in mind, however, we must acknowledge the continued relevance of country-to-country forms of relational consciousness, which express themselves in two main ways: first, through the emulation of ideas, strategies and practices, via the circulation and interaction of people (activists, organizers) around the world. The Arab spring might be the most recent example of the power of imitation in international politics, but the post-1989 wave of democratization in Eastern Europe comes to mind, too. The second channel refers to people's implicit understandings of their country's place vis-à-vis other traditions and other polities. The study by Pouliot (2010) of the diplomatic field captures the connection between individual habitus and international relations especially well, and it offers a striking illustration of how individuals acting as representatives of their countries on the international scene come to "embody" these countries' structural properties.

Similarly, many Swedish political actors understand themselves as ambassadors of political goodwill, and this "mission" is very self-conscious both within the government and among the national population-from the flocks of missionaries heading from Sweden in the past, to the large number of joiners in international organizations today. The French, for their part, continue to live out their old legacy through their uncommon use of public protests-less, perhaps, as a reenactment of their own history than as a strong assertion of political-cultural distinctiveness in a Europeanized (or globalized) world where homogeneity is perceived as an increasing threat. By contrast, the populations of nations on the periphery of the world system do behave in ways that are consistent with a lower engagement in their own nation-state-with more passive politics (at least as measured by the WVS) and high levels of emigration. Finally, politicians everywhere frequently manipulate public representations of other nation-states in an effort to draw support or vilify certain policies. Most continental European countries are frequently described as "socialist" in U.S. political discourse, for instance. Regardless of whether such statements are adequate representations of some underlying reality, they do intervene in the very political activities that they allegedly describe (Weider, 1974).

Obviously, we cannot fully engage these kinds of concrete interstate relations here, let alone the sometimes violent geopolitics, that lies beneath the structuring of local political fields. While it is certainly possible to extrapolate, as we do with Sweden or Hungary above, some suggestive interpretations about people's political behavior from their country's position within the global political, economic, and cultural power structure, our purpose here has been more modest. Instead, we have been interested primarily in describing states as a product of their populations' position within a broader system of relations of behavioral proximity and distance, some of which are strongly determined through interstate relationships (e.g. the cases of Hungary and Poland, subject to German then Soviet influence in recent times) and some of which are less directly so (e.g. Argentina)

\subsection{Polity structure and individual action}

Importantly, the method has allowed us to produce a fairly simple framework for thinking about political differences across countries. By far the most pregnant dimension of variation has to do with the sheer volume of political engagement, whether it is of a contentious or a more institutionalized type. Thus, in our sample the politically active (in relative terms) nations of Scandinavia and the United States are opposed on the "volume" dimension to countries like Hungary, Poland, and Argentina. To be sure, the relative passivity evidenced by WVS survey respondents in these latter three cases (in 2005) might have its roots in these countries' common historical experience of authoritarian rule. But a closer examination of the cases, looking at the field of politics within, also suggests that the similar positions Hungary and Argentina occupy in the space of polities may be conditioned by different socializing experiences among these countries' respective citizenries. First, the rules of the political game obviously differ across these nations, if only due to their idiosyncratic historical paths. Second, the same political practices may be the object of substantively different uses but still produce the result that, overall, these countries' 
populations tend to "behave" similarly (that is, they tend to be positioned as less politically engaged than other nations in the sample). In that way geometric data analysis serves as a complement, rather than a substitute, to more in-depth comparisons (Breiger, 2009; Ragin, 2000). The latter are still necessary to make full sense of the patterns observed.

The second dimension, which we have called the temporal structure of political activity, overlaps to a great extent with the opposition between statist and societal modes of political sovereignty (Jepperson, 1993, 2002; Schofer \& FourcadeGourinchas, 2001). The third dimension opposes "taken-for-granted" modes of belonging to more "voluntary" ones and singles out countries along the corporate-non-corporate dimension as high contributors (with the membership-driven societies of Sweden and the Netherlands opposed to the more voluntary populations of France, the United States and Italy). Finally, the fourth dimension Factor opposes the class struggle to the moral dimension of political activity, with the Netherlands (on the side of human rights, peace, and the environment) and Denmark (on the side of labor militancy) as highest contributors.

But our aim is obviously not simply descriptive. The fact that patterns in 2004 can be interpreted, in no small measure, through the lens of the conceptual apparatus Jepperson and Meyer (1991) and Jepperson $(1993,2002)$ propose, suggests that, in spite of the extraordinary messiness of individual countries' histories, regularities tend to be long-lasting, supporting the production of a relatively stable conceptual framework. Thus, one contribution of this study is to have systematically grounded the neo-institutionalist concepts of stateness and corporateness (Jepperson, 1993, 2002) in empirical variations in the volume and rhythm of the political activities that individuals undertake. Certainly, each national political space is structured in a way that reflects its specific genesis, history, and the particular struggles that took place within it. These institutions and sedimented histories frame individuals' socialization into politics by shaping the range and nature of political actions, organizations, and meanings. In the end, relational analyses and techniques help us not only show that there is a discoverable order in these histories and struggles, but also reconstruct the very categories and objects of the comparison in a way that is, perhaps, truer to the phenomenology of individuals' experience of politics across nations.

\section{References}

Abbott, A. (2001). Chaos of disciplines. Chicago,Il: The University of Chicago Press.

Almond, G. A., \& Verba, S. (1963). The civic culture. Princeton, NJ: Princeton University Press.

Amable, B. (2003). The diversity of modern capitalism. Oxford: Oxford University Press.

Ancelovici, M. (2008). Social movements and protest politics. In A. Cole, P. Legalès, \& J. Lévy (Eds.), Developments in French politics 4 (pp. $74-91$ ).Palgrave Macmillan.

Ancelovici, M. (2009). 'Esquisse d'une théorie de la contestation: Bourdieu et le modèle du processus politique. Sociologie et Sociétés, 41(2), 39-61.

Bail, C. (2008). The configuration of symbolic boundaries against immigrants in Europe. American Sociological Review, 73(1), 37-59.

Birnbaum, P., \& Badie, B. (1983). The sociology of the state. Chicago, IL: University of Chicago Press.

Bonikowski, B. (2010). Cross-national interaction and cultural similarity: a relational analysis. International Journal of Comparative Sociology, 51, 315-348.

Bourdieu, P. (1984). Distinction. A social critique of the judgment of taste. Stanford: Stanford University Press.

Bourdieu, Pierre (1985). Social Space and the Genesis of Groups. Theory and Society, 14(6), 723-744.

Bourdieu, P. (1993). Public opinion does not exist. Sociology in question. Thousand Oaks, CA: Sage.

Bourdieu, P. (1996). The rules of art: genesis and structure of the literary field. Stanford, CA: Stanford University Press.

Bourdieu, P. (1998). Social space and symbolic space. Practical reason. Stanford: Stanford University Press1-18.

Bourdieu, P. (2005). Principles of an economic anthropology. In R. Smelser (Ed.), The handbook of economic sociology (pp. 75-89).Princeton, NJ: Princeton University Press.

Breiger, R. (2000). A Toolkit for Practice theory. Poetics, 27, 91-115.

Breiger, R. (2009). On the duality of cases and variables: correspondence analysis (CA) and qualitative comparative analysis (QCA). In D. Byme, \& C. Ragin (Eds.), The SAGE handbook of case-based methods (pp. 243-259).Thousand Oaks, CA: Sage.

Brubaker, R. (2004). Ethnicity without groups. Harvard, MA: Harvard University Press.

Bryson, B. (1996). Anything but heavy metal. American Sociological Review, 61(5), 884-899.

Collier, D., \& Collier, R. (1991). Shaping the political arena: critical junctures, the labor movement, and regime dynamics in Latin America. Princeton, NJ: Princeton Unviersity Press.

Curtis, J. E., Baer, D. E., \& Grabb, E. G. (2001). Nations of Joiners: Explaining Voluntary Association Membership in Democratic Societies. American Sociological Review, 66(6), 783-805.

de Tocqueville, A. (2000). Democracy in America. Chicago: University of Chicago Press.

De Nooy, W. (2003). Fields and networks: correspondence analysis and social network analysis in the framework of field theory. Poetics, 31(5-6), 305-327.

Derluguian, Georgi (2007). The Worlds Which the Portuguese, the Russians and the Poles created: Empires on Europe's Periphery. Lusotopie, 14(2), 3-10.

Desmond, M. (2014). Relational ethnography. Theory and Society, 43, 547-579.

Durkheim, E. (1997). Suicide. New York, NY: The Free Press.

Dyson, K. (1980). The state tradition in Western Europe. Oxford [England]: Martin Robertson.

Ekiert, G., \& Kubik, J. (1998). Contentious politics in new democracies: East Germany, Hungary, Poland and Slovakia, 1989-93. World Politics, 50(4), 547-581.

Eliasoph, N. (1998). Avoiding politics. how americans produce apathy in everyday life. Cambridge University Press.

Eliasoph, N., \& Lichterman, P. (2003). Culture in interaction. American Journal of Sociology, 108(4), 735-794.

Emirbayer, M. (1997). Manifesto for a Relational Sociology. American Journal of Sociology, 103(2), 281-317.

Emirbayer, M., \& Goldberg, C. A. (2005). Pragmatism, bourdieu and collective emotions in contentious politics. Theory and Society, 34(5), 469-518.

Enfield, N.J. 2010. “Tolerable Friends.” Berkeley Linguistic Society Proceedings. Available at http://pubman.mpdl.mpg.de/pubman/item/escidoc:388893:1/ component/escidoc:388892/Enfield 2007 Tolerable\%20Friends.pdf.

Esping-Andersen, G. (1990). The three worlds of welfare capitalism. Cambridge: Polity.

Fourcade, M. \& Schofer, E. Political structures and political mores: forms of political activity in comparative perspective. Sociological Science (Forthcoming) Fourcade, M. (2007). Theories of market and theories of society. American Behavioral Scientist, 50(8), 1015-1034.

Friedman, G. (1988). Strike success and union ideology: the United States and France, 1880-1914. The Journal of Economic History, 48(1), 1-25.

Garfinkel, H., \& Rawls, W. (2002). Ethnomethodology's program: working out Durkheim's aphorism. Lanham, Maryland: Rowman and Littlefield Publishers.

Ghaziani, A. \& Mohr, J. (eds.). 2014. Measuring culture. Theory and Society, 43 (special issue).

Goldberg, A. (2011). Mapping shared understandings using relational class analysis: the case of the cultural omnivore reexamined. American Journal of Sociology, 116(5), 1397-1436.

Multiple correspondence analysis and related methods. In M. Greenacre, \& J. Blasius (Eds.). Boca Raton, FL: Chapman \& Hall. 
Hankiss, E. (1989). Demobilization, self-mobilization and quasi-mobilization in Hungary, 1948-1987. Eastern European Politics and Societies, 3(1), 105-151. Harcourt, B. E. (2002). Measured interpretation: introducing the method of correspondence analysis to legal studies. University of Illinois Law Review979-1018. Herbst, S. (1992). Surveys in the public sphere: applying Bourdieu's critique of public opinion polls. International Journal of Public Opinion Research, 4(3), 220229.

Howard, M. M. (2002). Free not to participate: the weakness of civil society in post-communist Europe. Cambridge University Press. Inglehart, R., \& Welzel, C. (2005). Modernization, cultural change and democracy. New York and Cambridge: Cambridge University Press. Inglehart, R., \& Baker, W. (2000). Modernization, cultural change and the persistence of traditional values. American Sociological Review, 65(1), 19-51. Inglehart, R. (1990). Culture shift in advance d industrial society. Princeton: Princeton University Press.

Inglehart, R. (1997). Modernization and postmodernization: cultural, economic and political change in 43 societies. Princeton: Princeton University Press. Jepperson, R., \& Meyer, J. (1991). The public order and the construction of formal organizations. In W. P. Walter, \& P. J. DiMaggio (Eds.), The new institutionalism in organizational analysisChicago: University of Chicago Press.

Jepperson, R. (1993). National scripts: the varying construction of individualism and opinion across the modern nation-states. Yale University (unpublished Ph.D dissertation).

Jepperson, R. (2002). Political modernities: disentangling two underlying dimensions of institutional differentiation. Sociological Theory, $20(1), 61-85$. Kriesi, H., Koopmans, R., Duyvendak, J. W., \& Giugni, M. G. (1995). New social movements in Western Europe: a comparative analysis. UCL Press.

Laurison, D. 2015. The willingness to state an opinion: inequality, don't know response, and political participation. Forthcoming in Sociological Forum. Le Roux, B., \& Rouanet, H. (2005). Geometric data analysis: from correspondence analysis to structured data analysis. Dordrecht: Kluwer.

Lena, J., \& Petersen, R. (2008). Classification as culture: types and trajectories of music genres. American Sociological Review, 73(5), 697-718.

Lipset, S. M. (1961). Trade Unions and Social Structure I. Industrial Relations, 1(1), 75-89.

Lorrain, F., \& White, H. C. (1971). Structural equivalence of individuals in social networks. Journal of Mathematical Sociology, 1, 49-80.

MacIntyre, A., 1971. Is a science of comparative politics possible?. In: Against the self-images of the age; essays on ideology and philosophy. Alasdair Macintyre. New York : Schocken Books.

Martin, J. L. (2000). The relation of aggregate statistics and beliefs to culture and cognition. Poetics, 28, 5-20.

Martin, J. L. (2003). What is field theory? American Journal of Sociology, 109(1), 1-49.

McAdam, D., Tarrow, S., \& Tilly, C. (2001). Dynamics of contention. Cambridge, MA: Cambridge University Press.

Meyer, J., Boli, J., \& Thomas, G. (1997). World society and the nation-state. American Journal of Sociology, 103(1), 144-181.

Mische, A. (2007). Partisan publics. Communication and contention across Brazilian youth activist networks. Princeton, NJ: Princeton University Press.

Mohr, J. (1998). Measuring Meaning Structures. Annual Review of Sociology, 24, 345-370.

Mohr, J. \& Bogdanov P. (eds.). 2013. Topic models and the cultural sciences. Poetics Special issue, 41(6).

Parsons, T. (1963). On the concept of political power. Proceedings of the American Philosophical Society.

Petersen, R., \& Kern, R. (1996). Changing highbrow taste: from snob to omnivore. American Sociological Review, 64(5), $900-907$.

Pouliot, V. (2010). International security in practice: the politics of NATO-Russia diplomacy. Cambridge: Cambridge University Press.

Ragin, C. C. (2000). Fuzzy-set social science. University Chicago Press.

Rock, D. (1985). Argentina 1516-1982: from Spanish colonization to the Falklands War. Berkeley and Los Angeles, CA: University of California Press.

Sabato, H. (1992). Citizenship, political participation and the formation of the public sphere in Buenos Aires 1850-1880s. Past and Present, 136, 139-163.

Schofer, E., \& Fourcade-Gourinchas, M. (2001). The structural contexts of civic engagement: voluntary association membership in comparative perspective.

American Sociological Review, 66(6).

Schmitter, P. C. (1974). Still the century of corporatism? Review of Politics, 36, 85-131.

Seleny, A. (1999). Old political rationalities and new democracies: compromise and confrontation in Hungary and Poland. World Politics, 51(4), 48-519.

Sewell, W. H. (1996). Historical events as transformations of structures: inventing revolution at the Bastille. Theory and Society, 25(6), 841-881.

Silber, I. F. (1995). Space, fields and boundaries: the rise of spatial metaphors in contemporary sociological theory. Social Research, 62(2), $323-355$.

Swartz, D. (2013). Symbolic power, politics and intellectuals. The political sociology of Pierre Bourdieu. Chicago, IL: University of Chicago Press.

Swidler, A. (1986). Culture in action. Symbols and strategies. American Sociological Review, 51(2), $273-286$.

Tabachnick, B. G., \& Fidell, L. S. (2007). Using multivariate statistics, fifth ed. Boston, MA: Pearson.

Tilly, C. (1986). The contentious French. Cambridge, MA: Harvard University Press.

Tilly, C. (2008). Contentious performances. Cambridge University Press.

Vaisey, S., \& Lizardo, O. (2010). Can cultural worldviews influence network composition? Social Forces, 88(4), 1595-1618.

Wedeen, L. (2002). Conceptualizing culture: possibilities for political science. American Political Science Review, 4, 713-728.

Weider, D. L. (1974). Language and social reality. The Hague: Moulton.

Western, B. (1997). Between class and market. Princeton: Princeton University Press.

Whitehead, A. N. (1925). Science and the modern world. London: Macmillan.

Marion Fourcade is Professor of Sociology at UC Berkeley. Her work focuses on the study of national variations in knowledge and practice and spans a range of empirical objects, from the discipline of economics to forms of political mobilization to wine classifications and digital technologies.

Brian Lande holds a Ph.D. in Sociology from UC Berkeley and is a principal at PolisSolutions, a consulting firm specializing in the social factors of human, organizational, and design performance. He also does academic research on these topics.

Evan Schofer is Professor of Sociology at UC Irvine and specializes in the study of globalization, political participation, education, environmentalism, voluntary associations, and world society, among others. 